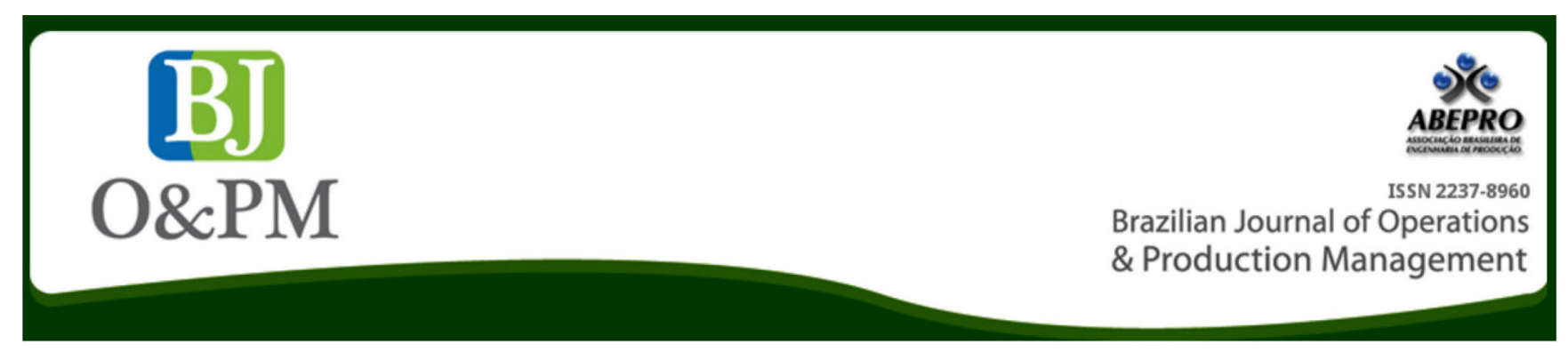

\title{
PROPOSAL FOR A WATER RESOURCE MANAGEMENT STRATEGY MODEL USING THE WATER FOOTPRINT CONCEPT
}

\author{
Leonardo Costa ${ }^{1}$, João Amato Neto ${ }^{1}$
}

1 São Paulo University

\begin{abstract}
We hereby present a proposal for a water stewardship strategy model, having the water footprint as a reference, developed from the results of a qualitative and exploratory research and by interviews with experts in the subject. The aim is to identify these experts' contributions to a water stewardship model as from the applicability of the water footprint concept. From the contribution provided by the experts' panel, as well as the authors' understanding of the content of the bibliographic research conducted, a water stewardship strategy model was proposed for producing goods and services as from the water footprint concept, structured as a Plan-Do-Check-Action stewardship model. This model sought to be supported on a holistic view of the sustainable management process of water resources, besides seeking to provide an innovative and comprehensive way to account for water use and consumption along with effluent disposal. Thus, it sought to contribute to a suitable risk management and might contribute as a necessary support for the development of operational and commercial strategies, contributing significantly to the sustainable development of an organization.
\end{abstract}

Keywords: Water Footprint, Water Resources, Sustainable Development. 


\section{INTRODUCTION}

The last years are marked as the period in which Brazil - a country comprising $12 \%$ of all drinking water on Earth (Araia, 2010) - was discovered vulnerable to water. Mainly the Southeast Region, the Country richest and most industrialized, presented well below average historical rainfall indexes, thus creating many supply problems (Instituto Nacional de Pesquisas Espaciais, 2014).

Factors for the Country's drought increase are not yet fully known, being the Amazonian Region ongoing deforesting as the most probable and, of the largest magnitude (Carvalho, 2014).

Added to this natural factor, the excess consumption, pollution levels increase (chemicals coming from the crops and from the industry, domestic sewer, besides of the high waste levels (Urban, 2012). To illustrate, it is estimated that water waste in Brazil reaches to $70 \%$ of the total water available for consumption (SOS Mata Atlântica, 2012).

Facing this challenging scenario, how can enterprises plan and become prepared to mitigate risks related to the shortage of this limited and irreplaceable input, intrinsically related to the production of products and services in all economic sectors?

The solution must involve, basically, aside of control policies formulation by the public and regulatory agencies, a strategy adequate by the organizations. As such, the objective of this article is to propose to the organizations an adequate water resources planning and management mechanism by means of the water footprint concept, in order to permit to identify means for consumption and waste reduction.

\section{TECHNICAL LITERATURE REVIEW}

\subsection{The Virtual Water Concept}

Before defining the water footprint concept, it is mandatory describing the key concept and one of the theoretical basis of its development: the virtual water concept

The virtual water concept was created by John Anthony Allan, of the King's College London, in 1993. Based on a study of the Israeli Professor Gideon Fishelson, that back in the late 1980's, declared that: "exporting water intensive products out of Israel, made not too much sense", due to the fact that countries import and export water in a virtual way, in other words, "by means of the quantity of water used to produce a given product".
The adjective "virtual" should be understood as the volume of water needed to produce a product, as such, is "virtually" incorporated into this product (Chapagain et Hoekstra, 2008). Referring to the fact that the majority of the water used to produce a product is not contained in such product, being just a small fraction of the water used to produce it. Actually, the concept is similar to the concepts of energy, land and work "incorporated", as such, one may refer to "incorporated water" (Hoekstra, 2009).

Allan (1998) elaborated on the idea of using the import of virtual water (mainly from food products) as a way to release the pressure on scarce local water resources of a given country. As such, the import of virtual water becomes an alternative water resource, besides of the endogenous aquiferous resources of a given region - the import of virtual water may also be called as "exogenous water".

By definition, the virtual water import refers to the used water volume (or polluted) in other countries to produce products and services imported and consumed in a given country. Virtual water export refers to the used water volume, used (or polluted) domestically in order to produce export bound products to be consumed in other countries (Hoekstra, 2009). The knowledge of virtual water flows entering and leaving a given place allows picturing the water depleters' direction, at this place (Chapagain et Hoekstra, 2008).

\subsection{Water Footprint Concept}

Using the virtual water concept, Professor Arjen Y. Hoekstra, developed the water footprint in 2002, with the objective to quantify the real and virtual water of products and services. The water footprint of a given place can be defined as the "total volume of fresh water to be used (or polluted) to produce products and services consumed by this local" (Hoekstra et Chapagain, 2008).

In this case, it is important to highlight two expressions: "freshwater", once it is scarce and not water in general; "consumed", as the products and services consumed by one given local can be produced locally by using local (real) water, as well as, produced elsewhere and imported by this local, by means of using the water from this other place (virtual water for the local importer). By the fact that one local consumes a product produced in another place, the water footprint concept says that, in this case, a virtual water import took place, thus making local water saving possible and that, once it had been needed to produce the now imported product or service.

The total water footprint of one local is divided into three categories: "blue" footprint (surface water and ground 
water), used to produce products and services locally consumed; "green" water footprint being the water volume that evaporates from the global "green" water resources (rain water kept in the soil) and, the "grey" water footprint that is the polluted water volume associated to the production of products and services locally consumed.

\section{RESEARCH METHODOLOGY}

\subsection{Approach and Research Methodology}

The chosen research method is of the qualitative type and, the chosen method was the exploratory research, being the data collected from a semi-structured questionnaire, with subsequent interviews (specialist's panel) regarding the water footprint concept.

Regarding the qualitative research approach, its distinctive feature is the emphasis in the perspective of the individual that is being studied or the concern in obtaining information regarding the perspectives of individuals and their natural environment is the research environment (Martins, 2010). The qualitative approach is justifiable, as this study aims to understand the studied object, through the perception of the specialists on the selected subject.

In regards to the exploratory studies, they are usually performed when the objective is to examine a given research subject or problem not enough studied, about which there are many questions or that have not been researched earlier. In other words, when the literature revision reveals that there are non-researched themes and ideas vaguely related with the research object. That is to stay, when it is intended to research subjects based on new perspectives and widen the already existing studies. They serve to familiarize us with relatively unknown phenomena (Sampieri et al., 2006).

As such, applying this research method is justifiable by the following reasons:

1. By means of the bibliographic research performed, it can be concluded that the applicability of the water footprint concept for a water stewardship model to produce products and services is still a scarcely studied subject, not presenting to the moment a much structured and disseminated theoretical body in the form of several applications. Sampieri et al. (2006) state that "this type of study is common in research, mainly in situations for which there is little information";

2. As the water footprint concept is relatively recent for the scientific-academic community, this concept is still under construction, as well as its applicabilities in a practical mod- el. Thus, the understanding and perceptions from specialists in the subject are pertinent on how the water footprint concept might contribute to the development of a water stewardship model for the production of goods and services.

\subsection{Selection and Research Sample}

The first step for the sample selection for this research was to delimit its population. Selltiz et al. (1987) state that a "population is the aggregate of all cases that fit into any set of pre-defined specifications". Therefore, in the case of this study, the research population were the specialists identified as experts in water footprint, either from the scientific-academic community or from public or private enterprises and NGO's.

Starting from the research population, a sample, which is a sub-group of the population that had its data gathered, was defined (Sampieri et al., 2006). Based on these authors, in order to select a sample, an analysis unit is to be defined (persons, organizations, communities, situations, events, etc.). For the qualitative approach, sample is an analysis unit or, by instance, a group of persons about whom data should be collected, but not necessarily being representative of the universe or, of the target population.

There are two types of samples: the probability sample: a sub-group of the population in which the elements have the same possibility to be chosen and the non-probability sample, a sub-group in which the elements' selection is independent from the probability, but rather from the research characteristics (Sampieri et al., 2006).

As such, for this survey of qualitative approach, using the exploratory method, a non-probability sample was selected from the analysis unit "persons" (experts in the water footprint concept), not necessarily representative of its population and, about which, data will be gathered. This selection happened informally, with no interest whatsoever to generalize the results achieved.

Due to the absence of a specific information or data source that would concentrate the list of experts (population) knowledgeable in the water footprint concept, the elected criteria for the sample selection was the knowledge, by the authors, subject experts acquired through bibliography reading, attendance to speeches and seminars and interaction records with both specific individuals, either members from the scientific-academic community or, part of the private enterprise community.

In line with the foreseen in the qualitative research approach, various experts in the subject (panel of experts) have been selected that are, actually, multiple evidence sources. 


\subsection{Data Gathering}

For data gathering of the intended information acquisition, it is necessary to use a method, adequate to a qualitative research.

The data gathering method for this research was the semi-structured questionnaire; in this way, it turned possible to perform the interviews in a more open and flexible way, by means of a conversation between the interviewer (authors of this research) and the interviewed (experts in the water footprint concept).

The semi-structured questionnaire was chosen as well as, according to Martins (2010). The structured interview is not adequate to the qualitative approach because, by structuring the interview, the researcher ends up imposing his vision of the research problem to the interviewed, thus making difficult the collection of the individual's perspective, which is exactly one of the distinct features of this kind of research approach.

\subsection{Research Sample Description}

A research sample used to carry out this exploratory study has been put together by water footprint concept experts. This sample of specialists was selected according to following criteria: i) those with previous knowledge by the authors of this research; ii) those acquainted to the author of this research and; iii) those recommended during the development of the interviews.

Twenty experts have been selected as research sample and they act at the types of organizations: public enterprises, private enterprises, academia, NGO's, government organs and private institutions. The reason for this research sample to contain specialists that belong to various types of organizations, was the possibility to obtain the opinion gathering regarding the water footprint concept in the multiple points of view, in other words, from its applicability already in use (case of some private enterprise) up to scholar and subject fans (academia and NGO's).

The initial approach with each specialist was the submission of an e-mail invitation requesting to join the research. The percentage answers accepting to participate were $70 \%$, with $60 \%$ of total (13 out of 20 experts). Those that initially agreed to participate in the research but have not been interviewed did not return the contact attempts to have the interview.

Overall, the interviews with the experts can be considered as very rewarding and, contributed considerably for the achievement of this study.
By the authors' understanding, there were interviewed experts that had a more accurate knowledge on the subject, either because they were already applying the concept at their enterprises or, in other situations, in consulting, or still dedicating academically to the subject. On the other side, some few interviewed individuals demonstrated having a barely over superficial knowledge on matter, but still not invalidating their interviews because in each of them, significant contributions occurred.

This judgment is in accordance to the theoretical statement of Martins (2010) that is based on the qualitative research theory. The answers may vary according to the concept of the organizational reality and the proximity to the studied phenomena. Furthermore, despite the fact that a semi-structured questionnaire has been used, at times the interviewer noted that the interviewed could not contribute in all questions; thus, it was decided to place questions beyond the previous established script.

At times when the interviewed showed more accurate knowledge in any given question of the questionnaire but, not so in others, the interviewer tried to extract the most information possible in the ones the interviewed showed experience. In the authors' understanding, this has considerably enriched the content.

Therefore, the interviews for this exploratory research accomplished their objective to identify the contributions of the water footprint concept for a model of water stewardship, resulting in the stewardship model proposal described as follows.

\section{PROPOSAL FOR A WATER RESOURCE STEWARDSHIP MODEL, FOR THE PRODUCTION OF PRODUCTS AND SERVICES, STARTING FROM THE WATER FOOTPRINT CONCEPT}

The proposed water stewardship model is divided in the following phases: Plan (Governance Practices, Policies and Guidelines Development, Regulatory Compliance and Risks \& Opportunities Identification), Do (Carry out the Action Plan for the Water \& Effluent Stewardship), Check (Action Monitoring, Indicators, Goals and Reports of Information and Results) and, Action (Water Stewardship Model Revision).

\subsection{Step: Plan}

\subsubsection{Governance Practices}

Once the water footprint concept allows the development of a water usage diagnosis, in case this gets combined 
with the existing data extracted from a risk management analysis, besides the development of correlated strategies, this set of applicabilities might result in argumentation to convince and, in the future, the organization's leadership commitment in relation to the strategic importance of water stewardship. All the information generated by the use of the water footprint is to be translated in a strategic context for the enterprise.

For the higher administration, probably the most important will be the group of capabilities of the water footprint concept (diagnosis, risk management and, strategy) and, whether the intended results are being obtained, or not. For instance: for an enterprise's investment decision, the information (among many other pieces of information needed), obtained on the use and availability of the regional water resources (diagnosis), indicates the place with the lowest possible risk (potential risk management, e.g., considering future water availability). As such, this information will be extremely useful for the strategy definition for the organization.

The experts on the subject, in general, agree that the water footprint concept is of great importance for the water stewardship of an enterprise and it's early adoption should start from the leadership, although some demonstrate certain degree of scepticism in regards to have an organization implementing a water stewardship model, either by lack of knowledge in terms of the importance of water for the business as such or by lack of pressure of the interested involved parties.

\subsubsection{Policies and Guidelines Development}

The proposal of policies and guidelines must follow the sequence of the three applicabilities (diagnosis - risk management - strategy elaboration, considering that these are not separately applicable but rather, are interdependent) and without the presumption to exhaust all feasible possibilities, as policies and guidelines might vary among organizations, depending of their maturity level in regards to the subject and to the characteristics inherent to their action sector. As such, policies and guidelines suggested in this phase might be considered as macro-orientations.

As an example, a first policy could be the determination of the development and implementation of action plans for the water management of the organization, with the objective of minimizing its use and the effluents' discharge, focusing on the direct operations, supply chain and the watershed basin where operating. Each action is to be preceded by the applicability of the water footprint concept diagnostic, in order to identify quantitatively the real situation of each project, determining short, medium and long range goals, as well as the follow-up of the management indicators, applicable for each developed action.

By analyzing the experts' answers, it can be noted that, aside of being too superficial, there has not been consensus as to the need to develop water stewardship management policies and guidelines by the organizations. While some specialists state that the water footprint concept might be used for the policies and guidelines construction in a given water stewardship model and suggest that these could be part of actions, such as water usage reduction in conjunction with risk evaluation tools, other showed pessimism in regards to the perception, by the enterprises, of the water stewardship importance and, furthermore, they did not perceive that the water footprint concept might improve the resource's management.

\subsubsection{Regulatory Compliance}

For a proper regulatory compliance, the organizations must actively act both in a reactive way as well as in a proactive way, in order to avoid having fines and penalties applied and, in extreme cases, to have its operation rights terminated due to regulatory non-compliances.

The organizations must identify the compliance to present legislation and public policies that restrict water use and consumption, impose limits to wastewater discharge and penalize water bodies' pollution and incident contamination, besides suggesting the development of the internal infrastructure to handle regulatory and legal compliance in all levels: local, state and nationwide.

This can be met with the support of the applicability of the diagnosis of the water footprint concept, by means of the green, blue and grey water footprints accounting. The blue water footprint will allow the enterprise to manage its intensity and understand the water resources usage limits, as determined by its grant, for instance, meanwhile the grey water footprint will allow the enterprise to control the water quality limits returning to the environment, as defined by law. The green water footprint, applicable to the production of agricultural products, will allow the enterprise, based on yearly rainfall trends in their production region, to forecast the need to use irrigation water (blue water footprint) and possible limits imposed to this type of use for the available water resources, if applicable. The applicability of risk management for the water footprint concept is important as well, to avoid contamination risks and water bodies' pollution.

Regarding the experts' opinion, the majority believes that there might appear a water management legislation for enterprises, based on the water footprint concept. De- 
spite the existing laws that already contain premises of the concept, such as the offer demand comparisons, this future regulatory benchmark might imply in many restrictions and opposing action movements from the enterprises due to the following possible factors: maximum allowable water footprint reference values, too demanding decrease requirements for the water footprint that might be contrary to the local reality, associating to the product water footprint values without considering the local conditions that were produced in the places, what might create entrance barriers in specific markets.

\subsubsection{Risks and Opportunities Identification}

Orr et al. (2009) state that the water footprint is useful when helping the enterprise in decision taking regarding the best production process practice, to understand the dependence of the suppliers in relation to water and, how to comply with government regulations. It further helps in the risks identification, such as reputation, costs originated by regulatory changes, etc.

The idea in this phase is to suggest the organization to identify a series of potential risks related to its water management, either direct operations, as well as, the supply chain, allowing enterprises to develop ways to mitigate them and further, to identify opportunities by means of the sustainable use of water, in a way to obtain competitive advantages in relation to its competitors.

Risk identification is to be achieved through the support of other risk assessment and management tools, which the organization sees best applicable and effective, subsidized by quantitative information obtained through the applicability of the water footprint concept diagnosis. For example:

- Through the total water footprint from products / services, from the business itself, added to the use of the Global Water Tool (GWT), which has, as entry data, the total local water footprint, thus making it possible to foresee if any given operation is located in any present or future water stress region;

- In order to create commercial strategies, consider not only the flow values (real and virtual water) for the water footprint; however, the cost of opportunity also involved (Wichelns, 2010) dealing with land availability, labour, knowledge and capital, competitivity (comparative advantage) in certain types of production, support and import duties (Chapagain et Hoekstra, 2008);

- It is suggested as well, to identify the existence and the tariff's policies related to water usage in the watershed. The change of vision of the organizations, just looking into the enterprise in order to deal with all questions and interested parties of its own operating watershed is a very important element of the water footprint concept and, it is to be considered that, in many Brazilian rivers there is an existing charge on the water and that the trend for this charge is extended countrywide. This fact will certainly cause impact on the production costs of the organizations.

The expert's opinions in relation to this phase of the management model concentrated in the importance of the organizations to identify present and future water availability risks that might cause the most diverse impacts, from production cost increase to strategic consequences, such as the installation of a new unit in a given region, that might present water restrictions, with the enterprise not having foreseen this situation at the decision taking moment.

Other identified risks have been the need to act at the supply chain as it might happen in many situations in which the enterprise spends considerable resources to reduce water footprint in direct operations when, actually, the largest footprint to be concentrated in its supply chain also the need to avoid risks related to water, with the interested parties. All these risks might case impacts, to the point of the enterprise's survival.

Furthermore, as opportunities, they suggested that the water footprint concept applicabilities might help the organizations to identify which is the best location to develop an enterprise, considering water usage projections, besides suggesting the creation of new technologies to be used in arid places.

\subsection{Step: Do}

\subsubsection{Carry Out Action Plan for the Water and Effluent Management}

This step is based on the development and implementing of enterprises' action plans for the water management, aiming to minimize its use and wastewater disposal, focusing on direct operations, supply chain and the influence on the watershed.

It is important to highlight that all actions developed in this phase must count with its respective management indicators (might be combined with performance indicators, already being used by the organizations) and goals, in order to best manage them, thus attaining ongoing improvements for the water stewardship plan.

Very important suggestion of an interviewed specialist, suggesting that the action plan for the water and wastewa- 
ter management, with consequent reduction for the total water footprint value of an organization, be implemented in the following sequence of activities:

- Carrying out water consumption and wastewater disposal by sectors, along the plant's production process, by means of the installation of water meters and flowmeter;

- Identifying water \& wastewater/effluents' losses along the processes;

- Modifying processes, through the suggested action plans, in order to reduce the organization's total water footprint.

Finally, it is important that the organizations pay attention at two important factors before implementing the action plans at this phase. these factors are preceded of the water footprint accounting: the importance of using reliable data for the water footprint calculation and the careful interpretation of the calculation results.

On the importance of using trustworthy data for the footprint calculations, the interviewed experts / specialists answered, at the requested question, to mention the water footprint concept weaknesses as there are many difficulties to do so.

Multiple factors have been pointed out to reach to this conclusion, such as: indirect data are not too well accounted for, the type of data that will be used to feed the calculations are not of free public access, it is necessary to use many average data to calculate the green water footprint and, there are difficulties finding data on the grey water footprint from the organizations, as well as finding the data that might be used for greater calculation credibility, mainly when dealing with historical data.

In respect to the needed care for the calculation results interpretation, the experts pointed out that there is criticism regarding green water footprint calculation. Apart from discussions on how to calculate this footprint, they might contain distortions, due to the fact that evapotranspiration data is very high in Brazil; nevertheless, there is a lot of water in the Country. This might induce to a results interpretation error, because, in absolute terms, not considering water availability, the water footprint tends to present a high value, which does not mean that it points to the worst conditions in regards to a country presenting low green water footprint, due to low evapotranspiration levels but, conversely, presents a high blue water footprint, considering the latter more costly and with greater environmental impact, to mention.

As to the grey water footprint, care should be taken regarding data interpretation in order to avoid incentivizing, in the wrong way, the production in lesser limitating countries under the effluent water disposal legal point of view, rather than rewarding countries that have restrictions of pollutants and more restrictive quality parameters for the disposal of effluents.

\subsection{Step: Check}

\subsubsection{Action, Indicators and Goals Monitoring}

This phase of the water stewardship model has the objective to monitor the goals and indicators as defined in the previous step for the implemented action plans, in order to check the effectiveness and the efficiency of each one and, through a continuous improvement process, they might be redefined and improved, if applicable, at the "Action" step.

The water footprint concept permits monitoring not only the organizations' water use and effluent disposal from their direct operations, but it also definitely provides them a more holistic view in terms of their value chain:

1. Through the implemented indicators and goals for the actions developed and involving the three applicabilities of the water footprint concept, these will allow the enterprise monitoring these actions along their whole value chain as well as at the watershed, considering the relations with the interested parties;

2. It is suggested to monitor and evaluate the indicators and action goals that might be implemented to mitigate the remaining Sustainability risks involved in the organizations' water management, including their value chain and watershed where active.

3. Considering this to be an internationally used concept, allowing comparability with other enterprises of the same segment and the possibility of promoting internal and external benchmarking, aiming at the interchange of the good practices and the continuous improvements, in the sustainable use of water.

As to the last, as stated by Pfister et Ridoutt (2010), this requires special attention by the organizations, since there is still no clear relation between the water footprint and the potential social-environmental damages due to the excessive extraction of this natural resource from a place showing water restrictions. Isolatedly, the quantitative information on the water footprint is not too useful; in other words, it is important to relate it with qualitative information, as well as with the financial performance of the organizations, in order to have a broad and sustainable approach for the water stewardship. 
In relation to external benchmarking, this can be attained by comparing the action plan results, indicators and, the organizations' water management goals among peers and other productive sectors and, further, to contribute to the organization's water footprint data bank. Again, it is important to highlight the need of careful evaluation as the social-environmental conditions might vary considerably among different products and services' production places.

Experts state that, what needs to be done at this phase is the monitoring of the action plans, indicators and goals, achieved in an integrated way, not only considering the organizations' direct operations, but in the whole value chain and watershed.

Still, this is done in a superficial way by the enterprises and the water footprint concept might promote this integrated and systematic monitoring. Thus, the experts suggest the separation of quantitative information of the green, blue and grey water footprints and later on, the internal and external as well. This way the real and virtual water flows, and the water losses from all and by each process are monitored, as well as the installation of rain stations and fluviometric ones (measurement of river flows) in multiple places of the river basin and adding action plans, indicators and goals to the Environmental Management System of the organization.

\subsubsection{Reporting of Information and Results}

The information and results (indicators and goals) of the actions carried out in the water management model of an organization might be made available for their internal and external audiences. This information and results reporting might be achieved by internal and external publications, such as the Sustainability Reports.

These results and information must contain the quantitative data resulting from the water footprint concept application, such as specific production features (production in water scarce/abundant places, social-environmental impacts, etc.) due to the fact that this information vary among the specific places.

Specialists, in their majority, agree that the enterprises' water management model reporting and results of information, either for internal or external audiences, is important as this signifies transparency, shows the enterprise commitment with the sustainable use of water, opens possibility to achieve new markets, mainly the European ones that might request such information in a commercial transaction, as well as, due to the trend in the pressure increase from the interested parties, to know about this information, as investors, consumers, watershed management committee, etc.
Those who showed restrictions to the reporting, state that this is strategic information for the organizations. As such, there must be a reason for its availability that might be related to commercial issues and pressure from the interested parties.

Thus, the water management model results and information of an enterprise might be reported through the Sustainability Reports, for instance. Meanwhile, the quantitative information and results from the water footprint are to be contextualized, according to products/services' production; in other words, qualitative information about water usage is to be shown (social-environmental context, impact on the watershed, water quality, etc.)

As to the water footprint information reporting of a given product by means of its' labelling, the experts suggest that the organization should be careful when making this information available. Besides the fact that production specifics, and the water use and availability vary from place to place, presently there is much more use of global water use \& consumption averages, which might lead to comparability errors and the vision that a given product is more water sustainable in relation to other similar products, but in reality, it is not.

This question might even deepen into questions that impose risks to the trade balance and customs issues of a country, because trade restrictions might be imposed to non-sustainable products in relation to water usage, which might cause large financial disruption for the organizations as such, and for a country, as a whole.

\subsection{Step: Action}

\subsubsection{Review of the Water Stewardship Model}

This last phase of the water stewardship model is the time for the organizations to revise the whole content of the previous phases, aiming at improving and standardizing actions that generated positive results and, to change those that did not meet the expectations, always in the pursuit of ongoing improvements.

Specifically, in regards to the water footprint, the efficiency of the application of the applicabilities has to be assessed in the water stewardship plan as a whole: the benefits attained, difficulties found, effectiveness of the suggested applicabilities, etc. and always in the search for improving their use.

On this question, only a small part of the experts mentioned some considerations. The majority stated they had 
nothing more to add. Some comments, such as the combination of the water footprint concept with the Life Cycle Analysis and the ISO Std. for water footprint, product or service valuation in regards to the local water consumption have already been considered in the earlier phases of the suggested management model.

Another question approached refers to the complexity of the water footprint concept implementation and its applicabilities by any given enterprise. In this regard, the authors of this survey understand that this is still quite a recent concept that is going through a series of improvements (as for the green and grey water footprint calculations, for instance) and is still in its early stage of implementation by the majority of the enterprises. Therefore, just with the ongoing improvements of practical application processes and learning, this complexity and difficulties tend to reduce, counting on the ever growing and joining the concept established by the enterprises, thus contributing more and more to the sustainable water usage stewardship.

\section{CONCLUSIONS}

It is clear that the applicability of the results obtained in this research is wide, based on the objective to propose a water stewardship strategy model that is applicable to public entities, private enterprises of any size or industry. Certainly, the model might be adapted, subject to the specific characteristics of each organization and its industrial field, besides of the strategy of each enterprise and its understanding of the subject.

Some limitations of the proposed model may be pointed out, as: lack of specific action analysis for each type of industry and the possible considerations of the complexity, even when it is seen from the enterprises' side, due to the still incipient level of understanding regarding the water footprint concept, as well as the level of importance of the water management for the sustainability of the organizations.

Considering it a relatively new subject, as well as demanding further and wider understanding of its capabilities, the water footprint concept needs to be submitted to actual checkings by the organizations that really understand that water is a matter of priority for their business to endure.

The answers obtained through the specialists'/experts' panel and the authors' understanding of the referential theoretical content contributed to the proposal of a water stewardship model structure, starting from the water footprint concept, once the latter can rely on practical application elements.

Thus, as a result of this research, it can be highlighted that the proposed water stewardship model can be applied to multiple sized organizations and segments, as it relies on the proposed content, starting from the good enterprises' water management practices, improved by the theoretical reference content and the contributions experienced by the specialists / experts in the water footprint concept.

In order to make the model effective, it is necessary for its users to understand the conceptual theory of the water footprint. So far, this is not totally true, since there are some difficulties in the theoretical understanding and there is the mistake of just analysing quantitative information. Thus, differently from the proposed model, this evaluation must be achieved by combining with the qualitative information as well.

With the trend to have the subject "water" becoming increasingly more important in the discussions regarding the ways for a sustainable development of the whole society, it is understood that this research might provide a feasible way towards this objective.

\section{REFERENCES}

Allan, J.A. (1998), Virtual Water: A Strategic Resource Global solutions to Regional Deficits. Ground Water, Vol. 36, No. 4, pp. 545-546, available at: http://onlinelibrary.wiley. com/doi/10.1111/j.1745-6584.1998.tb02825.x/abstract (Accessed on July 25, 2012).

Araia, E. (2009), Água doce: O ouro do século 21. Revista Planeta 438. Available at: http://revistaplaneta.terra.com.br/ secao/meio-ambiente/agua-doce-o-ouro-do-seculo-21 (Accessed on March 13, 2013).

Instituto Nacional de Pesquisas Espaciais (2014), Boletim Infoclima. Available at: http://infoclima.cptec.inpe.br/ (Accessed on March 13, 2013).

Carvalho, E. (2014), Novo estudo liga desmatamento da Amazônia a seca no país. Available at: http://amazonia.org.br/2014/10/novo-estudo-liga-desmatamento-da-amaz\%C3\%B4nia-a-seca-no-pa\%C3\%ADs/ (Accessed on April 23, 2013).

Chapagain, A.K., A.Y. Hoekstra. (2008), The global component of freshwater demand and supply: an assessment of virtual water flows between nations as a result of trade in agricultural and industrial products. Water International, Vol. 33, No. 1, pp. 19-32.

Hoekstra, A.Y. (2009), Human appropriation of natural capital: A comparison of ecological footprint and water footprint analysis. Ecological Economics, Vol. 68, No. 7, pp. 1963-1974.

Hoekstra A. Y., A. K. Chapagain. (2008), Globalization of Water: Sharing the Planet's Freshwater Resources. 1st Edition. Malden (EUA): Blackwell Publishing. 
Martins, R. A. (2010), Abordagens Quantitativa e Qualitativa. In: Miguel, P. A. C. (Org.). Metodologia de Pesquisa em Engenharia de Produção e Gestão de Operações. Rio de Janeiro: Elsevier. pp. 45-61.

Orr, S., Milà i Canals, L., Chenoweth, J., Chapagain, A.K., Antón, A., R. Clift. (2009), Assessing freshwater use impacts in LCA: Part 1-inventory modelling and characterisation factors for the main impact pathways. International Journal of Life Cycle Assessment, Vol. 14, No. 1, pp. 28-42.

Pfister, S., B.G. Ridoutt. (2010), Projected water consumption in future global agriculture: Scenarios and related impacts. Science of the Total Environment, Vol. 409, No. 20, pp. 4206-4216.

Sampieri, R. H., Collado, C. H., P.B. Lucio, P. B. (2006), Metodologia de Pesquisa. 3rd Edition. São Paulo: McGraw-Hill.

Selltiz, C.; Wrightsman, L. S.; Cook, S. W. (1987), Métodos de Pesquisa nas Relações Sociais: Delineamentos de Pesquisa.
Organizer of the 4th North-American Edition: Louise H. Kidder. Translation from Maria Martha Hubner d'Oliveira, Miriam Marinotti Del Rey. Coordinators of the 2nd Brazilian Edition: José Roberto Malufe, Bernadete A. Gatti. 2nd Edition. São Paulo: EPU.

SOS Mata Atlântica. (2012), São Paulo - Ameaças à Água. Rede de Águas. Available at: http://www.rededasaguas.org. $\mathrm{br} / q u e s t a o-a g u a / a m e a c a s-a-a g u a$ (Accessed on May 18, 2013).

Urban T. (2012), Falta de água na Terra é preocupação presente e futura. Available at: http://hugoprado.blogspot.com. br/2012/05/falta-de-agua-na-terra-e-preocupacao.html (Accessed on May 18, 2013).

Wichelns, D. (2010), Virtual water and water footprints offer limited insight regarding important policy questions. International Journal of Water Resources Development, Vol. 26, No. 4, pp. 639-651. 